\title{
Proposição de um modelo de precificação de mão-de-obra como instrumento de gestão na atividade fumageira da região sul
}

Doutorado em Controladoria e Contabilidade pela Universidade de São Paulo - USP Professor da Universidade Federal do Rio Grande do Sul - UFRGS Av. João Pessoa, 52. Centro. Porto Alegre/RS. CEP: 90000-000 E-mail:pschmidt@ufrgs.br

Jose Luiz dos Santos Doutorado em Economia pela Universidade Federal do Rio Grande do Sul - UFRGS Professor da Faculdade São Francisco de Assis - UNIFIN Av. Sertório, 253. Navegantes. Porto Alegre/RS. CEP: 91120-001 E-mail: joseluiz@unifin.com.br

Luciane Alves Fernandes Doutorado em Agronegócios pela Universidade Federal do Rio Grande do Sul - UFRGS Professora da Faculdade São Francisco de Assis - UNIFIN Av. Sertório, 253. Navegantes. Porto Alegre/RS. CEP: 91120-001 E-mail: luciane@unifin.com.br

Paulo Roberto Pinheiro Doutorado em Agronegócios pela Universidade Federal do Rio Grande do Sul - UFRGS Professor da Faculdade São Francisco de Assis - UNIFIN Av. Sertório, 253. Navegantes. Porto Alegre/RS. CEP: 91120-001 E-mail:p.pinheiro@unifin.com.br

\section{RESUMO}

O estudo consiste na elaboração de um modelo econômico de precificação que explique a percepção dos fumicultores e empresas fumageiras da região Sul do Brasil sobre o valor da remuneração do trabalho no custo de produção negociado entre as partes, visando à minimização dos conflitos existentes. Para tal, foi necessária a interpretação dos conceitos, natureza e mensuração do modelo de negócio existente, bem como a revisão e análise dos principais indicadores de mensuração a ele relacionados; analisar modelos de precificação existentes e elaborar um referencial teórico para embasar a construção de um novo modelo de precificação do custo do trabalho do fumicultor.

Palavras-chave: Precificação. Agronegócio. Conflitos. Fumicultura. Custo de oportunidade. 
Proposição de um modelo de precificação de mão-de-obra como instrumento de gestão na atividade fumageira da região sul

Paulo Schmidt, Jose Luiz dos Santos, Luciane Alves Fernandes, Paulo Roberto Pinheiro

\section{The purpose of a model of pricing labor-management tool tobacco activity in the} southern region of Brazil

\section{ABSTRACT}

The study consist in the elaboration of an economic model of pricing to explain the perception of the tobacco companies and fumicultors at southern Brazil about the value of the remuneration of labor in the production cost negotiated between the parties aimed at minimizing conflicts. This has required the interpretation of the concepts, nature and measurement of the existing business model, and the review and analysis of key indicators to measure related to it, analyze existing pricing models and theoretical framework that can based the construction of a new model pricing of the cost of the work of fumicultor.

Key Words: Pricing. Agribusiness. Conflicts. Tobacco culture. Cost of opportunity.

\section{INTRODUÇÃO}

O processo de mundialização acirrou a concorrência em setores da economia que até então gozavam de certa estabilidade de mercado (na relação entre oferta e demanda) para a obtenção de seus suprimentos. As empresas passaram a contar com uma maior facilidade na eventual substituição de fornecedores locais por fornecedores de outros países. As relações cooperativas e de longo prazo, existentes entre algumas empresas consumidoras (de determinados setores específicos dos países que recebiam estes aumentos repentinos de demanda) e seus tradicionais fornecedores, passaram a ser ameaçadas, dentre outros fatores, por comportamentos oportunistas destes últimos.

Para Jorde e Teece (1989), o aumento da competição global tem forçado acadêmicos, empresários e legisladores a revisar seus conceitos fundamentais sobre as relações de competição e de cooperação. Speckman et al. (1998) acreditam ser a gestão da cadeia de suprimentos o principal elemento para que se possa explorar adequadamente as vantagens competitivas sustentáveis por meio da redução de investimentos e custos, sem sacrifício da satisfação do cliente. Para o mesmo autor, essa revisão passa pela adoção de um modelo eficiente de relacionamento entre os 
Proposição de um modelo de precificação de mão-de-obra como instrumento de gestão na atividade fumageira da região sul Paulo Schmidt, Jose Luiz dos Santos, Luciane Alves Fernandes, Paulo Roberto Pinheiro

envolvidos, mais ou menos cooperativo, alterando-o quando as vantagens não mais forem obtidas.

O setor fumageiro, no que diz respeito à cadeia de suprimento estabelecida entre as empresas fumageiras e os produtores rurais, pode ser caracterizado por dois modelos com diferenças sensíveis com relação ao nível de cooperação estabelecido entre os seus componentes. O primeiro, o sistema de compra por leilões, pode ser descrito como altamente competitivo e o segundo, o sistema integrado, tendendo ao estabelecimento de relações mais cooperativas, sistema adotado pelas indústrias de tabaco do Sul do Brasil (ZAWISLACK, 2000).

Segundo o autor citado, o sistema de leilões é utilizado pelas empresas fumageiras de países como o Zimbabwe e os Estados Unidos para a aquisição das suas safras. Nesse sistema não há vínculo contratual entre o produtor e as empresas compradoras de fumo. Isso significa que o preço passa a ser determinado, exclusivamente, pela relação que existir no momento da comercialização entre a oferta e a demanda no mercado mundial de fumo, e pela qualidade da safra. Não há obrigação contratual por parte das empresas de compra de todo o volume produzido (run off the crop), com a formação de estoques eventualmente desnecessários e onerosos. A decisão sobre o volume de compra das empresas se dá de acordo com a demanda necessária para o seu consumo imediato e para a reposição de estoques estratégicos. Ou seja, em anos de oferta excessiva de fumo a indústria decide de quem, que classes, que volume e por quanto vai comprar. No caso de demanda elevada, o produtor tem a contrapartida das decisões. Assim sendo, uma das partes, produtor ou empresa, alternando-se de acordo com o nível de oferta ou de demanda do mercado, fica livre para beneficiar-se de movimentos especulativos, sempre em prejuízo da outra.

De outro lado, tem-se o modelo representado pelo sistema integrado de produção. Esse modelo traz vantagens e desvantagens balanceadas para as duas partes (produtor integrado e empresa), sendo a principal delas a manutenção da composição dos preços dentro da lógica do custo de produção. Ou seja, minimiza a influência da relação entre oferta e demanda do mercado internacional que ocasiona 
Proposição de um modelo de precificação de mão-de-obra como instrumento de gestão na atividade fumageira da região sul Paulo Schmidt, Jose Luiz dos Santos, Luciane Alves Fernandes, Paulo Roberto Pinheiro

movimentos especulativos no preço da safra nacional de fumo. Nesse sistema, como citado anteriormente, os riscos e benefícios são divididos de forma equilibrada.

Quando o mercado internacional está com alta demanda de fumo, as empresas integradoras são beneficiadas. Nesse caso, os produtores têm sua produção comprometida com as integradoras mediante contrato, pelo preço definido no início da safra, tendo como referência o custo de produção do fumo, não podendo beneficiar-se de eventuais movimentos especulativos. Quando acontece baixa demanda do mercado internacional ou baixa qualidade da safra, os produtores passam a ser favorecidos. Nesse caso, as empresas continuam com a obrigação contratual de compra de todo o volume produzido pelos integrados, com base no mesmo preço inicialmente estipulado (ZAWISLACK, 2000).

Zawislak (2000) ainda afirma que "as relações usuário-produtor, dentro do quadro de relações de fornecimento cada vez mais cooperativas entre empresas de uma cadeia produtiva, têm substituído os tradicionais leilões de fornecedores". Fica, portanto, fortalecida a necessidade de se procurar o estabelecimento de relações cooperativas em detrimento dos comportamentos oportunistas. Assim sendo, o estabelecimento de um relacionamento de parceria e de longo prazo, capaz de garantir certa "imunidade" dos preços aos movimentos especulativos do mercado global, mantendo-os dentro dos parâmetros das variações nos custos de produção, foi até hoje a principal razão para a permanência das empresas no sistema integrado.

Esse modelo deveria se mostrar capaz de gerar comprometimento e servir como mecanismo de estabilização, evitando comportamentos oportunistas incentivados por movimentos especulativos no mercado global desse produto. Portanto, o sistema integrado, através de um vínculo contratual entre a empresa fumageira e o produtor de fumo, deveria estabelecer uma relação de cooperação que, como tal, teria benefícios e obrigações equilibradas. No entanto, este ponto tem sido fortemente questionado pelas empresas fumageiras que atuam no Brasil e utilizam esse sistema.

Para o SINDIFUMO (2006), as transformações que deram origem ao movimento especulativo que ameaça a relação de cooperação tiveram início com a redução nos volumes plantados e a perda de clientes importantes, tanto que o Zimbabwe, terceiro 
Proposição de um modelo de precificação de mão-de-obra como instrumento de gestão na atividade fumageira da região sul

Paulo Schmidt, Jose Luiz dos Santos, Luciane Alves Fernandes, Paulo Roberto Pinheiro

maior exportador mundial de fumo, tem sofrido em função do recente agravamento da instabilidade política e social e dos conflitos fundiários. Essa demanda foi transferida, principalmente, para o Brasil.

Com esse aumento abrupto da sua, já grande, importância como fornecedor de fumo em folha para o mercado mundial, o Brasil ficou mais vulnerável à incidência de movimentos especulativos sobre a safra nacional. O sistema de integração (até então o único utilizado pelas empresas que atuam no país) teve seu equilíbrio comprometido pelo aumento da competitividade.

Para Zawislak (2000), as novas empresas que surgiram com o cenário especulativo passaram a utilizar um novo "sistema" de relacionamento com os produtores, altamente estimulador de comportamentos oportunistas. Essas empresas não possuem base produtiva integrada e, por ocasião da comercialização da safra fomentam a quebra unilateral dos contratos firmados entre as empresas integradoras e os seus produtores. Compram somente o volume que precisam, não carregando estoques desnecessários. Volume esse, composto exclusivamente por classes de fumo com alta demanda (rejeitando classes de difícil aceitação pelo mercado comprador internacional, uma vez que não possuem obrigação contratual de compra de toda a safra).

Como não fornecem insumos, não financiam investimentos e não oferecem assistência técnica ao produtor, têm custos muito baixos e riscos mínimos. Em resumo, agem sobre a base de produtores das empresas fumageiras integradoras, beneficiando-se da safra de fumo garantida pelo sistema de integração.

Como conseqüência dessa nova realidade que implica o aumento da inadimplência na elevação do número de rompimentos unilaterais de contratos e em custos mais altos para as empresas que optarem por continuar no sistema integrado, as empresas integradoras estão sendo forçadas a questionar o valor agregado pela relação de integração com os produtores de fumo.

Conforme o autor existe o reconhecimento, por parte do produtor integrado, das vantagens da manutenção do vínculo com as empresas integradoras em detrimento de comportamentos oportunistas gerados por situações de alta demanda. Este seria um 
Proposição de um modelo de precificação de mão-de-obra como instrumento de gestão na atividade fumageira da região sul

Paulo Schmidt, Jose Luiz dos Santos, Luciane Alves Fernandes, Paulo Roberto Pinheiro

importante fator para a decisão de permanência das empresas dentro dos moldes do sistema integrado. Ou, caso não haja este reconhecimento, para a tomada da decisão de migrar para o sistema de leilões.

Emerge destas constatações a relação do conflito da remuneração do valor do trabalho dos fumicultores que são proprietários de pequenas unidades familiares de produção e que necessitam da remuneração da sua produção pelas indústrias fumageiras para a reprodução do seu trabalho, conflitando com a necessidade de redução de custos das empresas fumageiras para o seu crescimento e sustentabilidade econômica.

\section{REFERENCIAL TEÓRICO}

\subsection{0 sistema agrícola integrado}

Segundo lório (1994), o sistema integrado de produção agroindustrial consiste em que mediante um contrato formal ou verbal, o pequeno produtor passar a produzir determinada matéria-prima, vendendo-a exclusivamente para a agroindústria com a qual tem contrato. A agroindústria, por seu turno, se encarrega da assistência técnica, do fornecimento de insumos e, às vezes, do financiamento de instalações necessárias e, ao final de cada safra, da compra da produção. A integração pode ter sua forma característica de inserção nos complexos agroindustriais, dependendo do tipo de produto envolvido no processo, de duas formas: horizontal ou vertical.

Segundo Ferreira (1995), os três níveis de transferência de funções produtivas e de gestão da agricultura para a agroindústria são:

- Contrato de compra e venda: em que somente são especificadas as condições de entrega e de preço; o comprador, portanto, não exerce controle sobre as técnicas e o processo de produção, em alguns casos, estabelecem certas cláusulas sobre a quantidade e qualidade dos produtos;

- Contrato de transferência parcial: nesse tipo de contrato, o comprador intervém diretamente nos fatores de produção utilizados na exploração 
Proposição de um modelo de precificação de mão-de-obra como instrumento de gestão na atividade fumageira da região sul Paulo Schmidt, Jose Luiz dos Santos, Luciane Alves Fernandes, Paulo Roberto Pinheiro agrícola e oferece sua assistência ao agricultor por intermédio, principalmente, dos seus serviços técnicos. O agricultor conserva a propriedade do produto, objeto do contrato, até o momento de sua entrega;

- Contrato de transferência plena: esse tipo de contrato inclui, além das cláusulas de comercialização e de produção presentes nos demais tipos, a transferência de uma parte importante ou de todas as funções de gestão da empresa, como o risco e o controle dos métodos de produção. É o comprador que detém a propriedade dos produtos. O agricultor se restringe a fornecer suas instalações e o trabalho. Dessa forma, o sistema integrado de produção pode ser classificado como uma relação de cooperação, mais especificamente, como uma relação do tipo usuárioprodutor.

De maneira mais específica, o modelo de integração adotado no Brasil pelas empresas fumageiras é um modelo de integração vertical formalizado através de contratos de transferência parcial, uma vez que os produtores integrados mantêm a propriedade do produto até o momento da entrega.

Portanto, o sistema integrado, através de um vínculo contratual entre a empresa fumageira e o produtor de fumo, deve estabelecer uma relação de cooperação que, como tal, tem benefícios e obrigações equilibradas.

\subsection{Agricultura familiar}

Atualmente, o fumo é o principal cultivo não alimentício em todos os continentes. De acordo com a Associação dos Fumicultores do Brasil (AFUBRA, 2006), a produção anual de fumo é de quase seis milhões de toneladas, e o crescimento previsto pela Organização das Nações Unidas para Agricultura e Alimentação (FAO) foi de 1\% a $1,5 \%$ a.a. até 2005 , movimentando cerca de 20 bilhões de dólares.

No Brasil, são cerca de 210.000 produtores de fumo que apresentam características bastante semelhantes. Por exemplo, os fumicultores na Região Sul do Brasil possuem propriedades de em média, 18,5 hectares, e a mão-de-obra é em sua 
Proposição de um modelo de precificação de mão-de-obra como instrumento de gestão na atividade fumageira da região sul

Paulo Schmidt, Jose Luiz dos Santos, Luciane Alves Fernandes, Paulo Roberto Pinheiro

esmagadora maioria familiar. As mais de 153.000 famílias produtoras possuem em média 3,4 integrantes cada, e contratam por ano aproximadamente 40.000 empregados temporários. Aproximadamente 2,2 milhões de pessoas são empregadas no setor fumageiro. Dessas, 33\% estão ligadas diretamente à lavoura de fumo, totalizando 723.000 trabalhadores (SINDIFUMO, 2006).

Apesar das diversas crises econômicas brasileiras das últimas décadas, os fumicultores têm conseguido manter-se graças ao caráter familiar dessa atividade. Fazse necessário aqui conceituar a agricultura familiar. Para tanto, é necessário o estudo de um número amplo de variáveis, que apresentam pesos e significados diferenciados, em relação ao contexto estudado.

Agricultura familiar é aquela em que a família, ao mesmo tempo em que é proprietária dos meios de produção, assume o trabalho no estabelecimento produtivo. É um conceito genérico, que apresenta diferentes situações em condições específicas e particulares.

Segundo Veiga (1996), agricultor familiar é todo aquele (a) agricultor (a) que tem na agricultura sua principal fonte de renda $(+80 \%)$ e que a base da força de trabalho utilizada no estabelecimento seja desenvolvida por membros da família. É permitido o emprego de terceiros temporariamente, quando a atividade agrícola assim necessitar. Em caso de contratação de força de trabalho permanente externa à família, a mão-deobra familiar deve ser igual ou superior a $75 \%$ do total utilizado no estabelecimento.

Em um projeto conjunto do Instituto Nacional de Colonização e Reforma Agrária (INCRA) e a FAO, iniciado em 1995, baseado nos microdados do IBGE (essa é a denominação utilizada pelo IBGE para designar os arquivos contendo os dados individualizados de cada estabelecimento agropecuário), considerou-se estabelecimento integrante da agricultura familiar aquele dirigido pelo próprio produtor rural e que utiliza mais a mão-de-obra familiar que a contratada, conforme resumido no Quadro 1. 
Proposição de um modelo de precificação de mão-de-obra como instrumento de gestão na atividade fumageira da região sul Paulo Schmidt, Jose Luiz dos Santos, Luciane Alves Fernandes, Paulo Roberto Pinheiro

\begin{tabular}{|c|}
\hline Quadro 1 - Resumindo a metodologia de delimitação do universo \\
familiar
\end{tabular}

Fonte: MDA/INCRA, 2000.

\subsection{A agricultura familiar no Brasil}

Considerando a definição anteriormente apresentada, tem-se, na Tabela 1 abaixo, a distribuição dos estabelecimentos conforme as categorias socioeconômicas e alguns indicadores que dão a medida da sua importância.

Tabela 1 - Brasil - Estabelecimentos, Área, Valor Bruto da Produção(VBP) e Financiamento Total (FT), segundo as Categorias de Agricultura

\begin{tabular}{|c|c|c|c|c|c|c|c|c|}
\hline $\begin{array}{c}\text { Categoria } \\
\text { s }\end{array}$ & $\begin{array}{r}\text { Estab. } \\
\text { Total }\end{array}$ & $\begin{array}{c}\% \\
\text { Estab. } \\
\text { s/tota } \\
1\end{array}$ & $\begin{array}{c}\text { Área } \\
\text { Total } \\
\text { (mil } \\
\text { ha) }\end{array}$ & $\begin{array}{c}\text { \% Área } \\
\text { s/tota } \\
1\end{array}$ & $\begin{array}{c}\text { VBP } \\
\text { (R\$ mil) }\end{array}$ & \begin{tabular}{|c|}
$\%$ \\
VB \\
$\mathbf{P}$ \\
$\mathbf{s} /$ \\
total \\
\end{tabular} & $\begin{array}{c}\text { FT } \\
\text { (R\$ mil) }\end{array}$ & $\begin{array}{c}\% \text { FT } \\
\text { s/ } \\
\text { total }\end{array}$ \\
\hline Familiar & $\begin{array}{r}4.139 .36 \\
9\end{array}$ & 85,2 & $\begin{array}{r}107.76 \\
8\end{array}$ & 30,5 & $\begin{array}{r}18.117 .7 \\
25\end{array}$ & 37,9 & 937.828 & 25,3 \\
\hline Patronal & 554.501 & 11,4 & $\begin{array}{r}240.04 \\
2\end{array}$ & 67,9 & $\begin{array}{r}29.139 .8 \\
50\end{array}$ & 61,0 & $\begin{array}{r}2.735 .2 \\
76\end{array}$ & 73,8 \\
\hline $\begin{array}{l}\text { Instit. Pia/ } \\
\text { Religiosas. } \\
\text { Entidade }\end{array}$ & 7.143 & 0,2 & 263 & 0,1 & 72.327 & 0,1 & 2.716 & 0,1 \\
\hline $\begin{array}{l}\text { Pública } \\
\text { Não } \\
\text { identifi- } \\
\text { cado }\end{array}$ & 158.719 & 3,2 & 5.530 & 1,5 & 465.608 & 1,0 & 31.280 & 0,8 \\
\hline Total & $\begin{array}{r}4.859 .86 \\
4 \\
\end{array}$ & 100,0 & $\begin{array}{r}353.61 \\
1 \\
\end{array}$ & 100,0 & $\begin{array}{r}47.796 .4 \\
69 \\
\end{array}$ & $\begin{array}{r}100, \\
0 \\
\end{array}$ & $\begin{array}{r}3.707 .1 \\
12 \\
\end{array}$ & 100,0 \\
\hline
\end{tabular}

Fonte: Censo Agropecuário 1995/96 IBGE (in MDA/INCRA, 2000).

Destaca-se a grande participação da agricultura familiar no total de estabelecimentos agropecuários do país (85,2\%), embora desproporcional à sua participação na área $(30,5 \%)$ e nos financiamentos (25,3\%). Por outro lado, os estabelecimentos da agricultura familiar participam no valor bruto da produção de uma 
Proposição de um modelo de precificação de mão-de-obra como instrumento de gestão na
atividade fumageira da região sul Paulo Schmidt, Jose Luiz dos Santos, Luciane Alves Fernandes, Paulo Roberto Pinheiro

forma mais significativa $(37,9 \%)$ do que a sua participação no número de estabelecimentos.

A estrutura fundiária da agricultura familiar, de certa forma, repete a concentração observada na agricultura do país, de uma maneira geral. Conforme a Tabela 2 abaixo, 39,8\% dos estabelecimentos familiares possuem menos de 5 ha e, em conjunto, detêm tão somente 3,0\% dos 107.768 ha reportados na Tabela 2. Em média, são estabelecimentos de apenas 1,9 hectares. No extremo oposto, 5,9\% dos estabelecimentos concentram 44,7\% daquela área, com uma média de 67,8 ha.

Tabela 2 - Brasil - Agricultura Familiar - Participação nos Estabelecimentos, na Área e Área Média, segundo os Grupos de Área Total (em ha)

\begin{tabular}{l|c|c|c}
\hline \multicolumn{1}{c|}{$\begin{array}{c}\text { Grupos de Área } \\
\text { Total }\end{array}$} & $\begin{array}{c}\text { \% nos } \\
\text { Estabelecimentos }\end{array}$ & \% na Área & Área Média \\
\hline Menos de 5 & 39,8 & 3,0 & 1,9 \\
5 a menos de 20 & 29,6 & 12,2 & 10,7 \\
20 a menos de 50 & 17,2 & 20,4 & 31,0 \\
50 a menos de 100 & 7,6 & 19,7 & 67,8 \\
100 ha a 15 & 5,9 & 44,7 & 198,0 \\
módulos regionais & & 26,0 \\
\hline
\end{tabular}

Fonte: MDA/INCRA, 2000.

Embora a agricultura familiar participe, na média, com $37,9 \%$ do valor bruto da produção (participação essa bastante elevada, considerando-se que conta apenas com $30,5 \%$ da área total e o seu exagerado número de estabelecimentos), há produtos nos quais o papel da agricultura familiar é de muito maior importância, conforme se pode ver na Tabela 3. 
Proposição de um modelo de precificação de mão-de-obra como instrumento de gestão na atividade fumageira da região sul

Paulo Schmidt, Jose Luiz dos Santos, Luciane Alves Fernandes, Paulo Roberto Pinheiro

Tabela 3 - Percentual do Valor Bruto da Produção (VBP) de Produtos Selecionados Produzidos nos Estabelecimentos Familiares.

\begin{tabular}{l|c}
\hline \multicolumn{1}{c|}{ Produto } & Participação no VBP Total \\
\hline Fumo & 97 \\
Mandioca & 84 \\
Feijão & 67 \\
Suinos & 58 \\
Pecuária leiteira & 52 \\
Milho & 49 \\
Aves/ovos & 40 \\
Soja & 32 \\
Arroz & 31 \\
Café & 25 \\
Pecuária de corte & 24 \\
\hline
\end{tabular}

Fonte: MDA/INCRA, 2000.

As culturas do fumo, mandioca e feijão despontam como quase que exclusivas da agricultura familiar. Chamam a atenção também os percentuais alcançados na pecuária de pequenos animais (suínos e aves/ovos), para o que deve estar contribuindo o sistema de produção integrada.

\section{METODOLOGIA}

A modelagem econômico-financeira da remuneração da mão de obra foi realizada de acordo com quatro elementos básicos:

- Coeficiente técnico dos dias/homem por hectare;

- Ponderação da produção das microregiões produtoras dos Estados da região Sul;

- Valor da diária pesquisada pelas indústrias fumageiras;

- Utilização do custo de oportunidade do produtor rural familiar. 
Proposição de um modelo de precificação de mão-de-obra como instrumento de gestão na atividade fumageira da região sul Paulo Schmidt, Jose Luiz dos Santos, Luciane Alves Fernandes, Paulo Roberto Pinheiro

\section{Coeficientes técnicos por atividade de mão-de-obra (dias/hectare):}

1) Canteiro de mudas: 9,64 dias

2) Plantio:

18,62 dias

3) Tratos culturais:

28,46 dias

4) Colheita:

53,10 dias

5) Classificação:

36,21 dias

6) Serviços diversos:

2,48 dias

Total

148,51 dias

- As atividades 1 a 3 que são realizadas exclusivamente por mão-de-obra familiar, são exercidas paralelamente a outras atividades de agricultura e pecuária de subsistência.

- As atividades 4 a 6 são exercidas por mão-de-obra familiar e por mão-de-obra terceirizada. Segundo pesquisa realizada por Fossatti e Freitas (2003), a proporcionalidade é de $82 \%$ familiar e $18 \%$ terceirizada.

\section{Ponderação da produção das microregiões produtoras dos Estados da região} Sul:

- Base ponderação utilizada no relatório "cálculo da média ponderada - outubro de $2006 "$.

Valor da diária pesquisada pelas indústrias fumageiras:

- Base ponderação das diárias utilizada no relatório "cálculo da média ponderada - outubro de 2006".

\section{Custo de oportunidade}

- Para este elemento buscou-se o custo de oportunidade do perfil do produtor familiar da cultura do fumo, adotando o parâmetro 0,5 para as atividades "1" a " 3 " e 1,0 para as atividades "4" a "6". 
A combinação destes elementos resulta no seguinte modelo matemático proposto para o custo da mão-de-obra por hectare:

$\mathrm{Va} M o=[(\mathrm{a} 1 \times 0,5 \mathrm{dt})+(\mathrm{a} 2 \times 0,5 \mathrm{dt})+(\mathrm{a} 3 \times 0,5 \mathrm{dt})+(\mathrm{a} 4 \times 1,0 \mathrm{dt})+(\mathrm{a} 5 \times 1,0 \mathrm{dt})+(\mathrm{a} 6 \mathrm{x}$ $1,0 \mathrm{dt})]$

Onde:

$$
\begin{aligned}
& \text { Va Mo = Valor da mão-de-obra } \\
& \text { a1 = Canteiro de mudas: 9,64 dias } \\
& \text { a2 = Plantio: } \quad 18,62 \text { dias } \\
& \text { a3 = Tratos culturais: } 28,46 \text { dias } \\
& \text { a4 = Colheita: } \quad 53,10 \text { dias } \\
& \text { a5 = Classificação: } \quad 36,21 \text { dias } \\
& \text { a6 = Serviços diversos: } 2,48 \text { dias } \\
& \mathrm{dt}=\text { diária terceirizada }
\end{aligned}
$$

Modelo matemático de validação do modelo proposto:

Va Mo $=[(\mathrm{a} 1 \times 0,5 \mathrm{sm})+(\mathrm{a} 2 \times 0,5 \mathrm{sm})+(\mathrm{a} 3 \times 0,5 \mathrm{sm})+(\mathrm{a} 4 \times 1,0 \mathrm{sm})+(\mathrm{a} 5 \times 1,0 \mathrm{sm})+$ $(\mathrm{a} 6 \times 1,0 \mathrm{sm})]$

Onde:

Va $\mathrm{Mo}=$ Valor da mão-de-obra

$$
\begin{aligned}
& \text { a1 = Canteiro de mudas: 9,64 dias } \\
& \text { a2 = Plantio: } \quad 18,62 \text { dias } \\
& \text { a3 =Tratos culturais: } 28,46 \text { dias } \\
& \text { a4 =Colheita: } \quad 53,10 \text { dias } \\
& \text { a5 =Classificação: } \quad 36,21 \text { dias } \\
& \text { a6 =Serviços diversos: 2,48 dias }
\end{aligned}
$$


Proposição de um modelo de precificação de mão-de-obra como instrumento de gestão na atividade fumageira da região sul Paulo Schmidt, Jose Luiz dos Santos, Luciane Alves Fernandes, Paulo Roberto Pinheiro sm = salário mínimo nacional diário

\section{PREMISSAS}

Este artigo contém a proposta de um modelo que será utilizado como referência para a definição de valor para o estabelecimento da remuneração da mão-de-obra no custo de produção na cultura do fumo.

Importante ressaltar que a proposta, por parte dos autores, considerou o conjunto de variáveis operacionais fornecidas pelo Sindifumo e por uma pesquisa de reconhecimento de campo, onde alguns produtores destacaram algumas informações importantes para o contexto dessa proposta.

Dentre as variáveis consideradas no modelo proposto, destacam-se as seguintes:

Os coeficientes técnicos de mão-de-obra são divididos nas seguintes fases:

1) Canteiro de mudas

2) Plantio

3) Tratos culturais

4) Colheita

5) Classificação

6) Serviços diversos

- Considera-se que as atividades 1 a 3 são realizadas exclusivamente por mãode-obra familiar;

- As atividades 4 a 6 são exercidas por mão-de-obra familiar e por mão-de-obra terceirizada;

- Levantamento das diárias de outubro/2006: relatório fornecido pelo Sindifumo do consolidado das indústrias por MRFH;

- Levantamento da ponderação da produção das microregiões fornecidos pelo Sindifumo, baseado em estudo realizado em dezembro de 1998 pelo Instituto CEPA/SC. 
Proposição de um modelo de precificação de mão-de-obra como instrumento de gestão na atividade fumageira da região sul

Paulo Schmidt, Jose Luiz dos Santos, Luciane Alves Fernandes, Paulo Roberto Pinheiro

\subsection{Visão geral}

Considerado que durante a fase de desenvolvimento das atividades " 1 " a " 3 " o produtor familiar não se dedica exclusivamente a cultura do fumo, dedicando-se a outros cultivos e tratos da terra para a sua subsistência, seu custo de oportunidade não apresenta o mesmo nível de relevância do momento das atividades "4" a "6". Este fato se dá em função de que as atividades "1" a "3" utilizam menos intensidade de mão-deobra podendo ser exercidas exclusivamente pelos membros das famílias dos agricultores.

Corroborando com este conceito, verificou-se que em levantamento de informações para subsidiar o modelo proposto, produtores destacaram que durante as fases da atividade "1" a " 3 ", caso haja a necessidade de contratação de mão-de-obra terceirizada a remuneração não excederia a $50 \%$ do que é pago durante o desenvolvimento das atividades "4" a "6". Esta constatação levou a considerar que o custo de oportunidade nas fases de " 1 " a " 3 " não pode ser superior a $50 \%$ do que representaria nas fases de "4" a "6". Portanto, adotou-se como uma das premissas do modelo o custo de oportunidade das fases " 1 " a " 3 " de $50 \%$ do custo de oportunidade das atividades das fases " 4 " a "6".

Segundo Backer e Jacobsen (1984), um custo de oportunidade é o custo resultante de uma alternativa à qual se tenha renunciado. No contexto econômico, frequentemente, o termo "custo de oportunidade" é substituído pelo termo "custo alternativo", como sinônimo. Portanto, neste estudo, considera-se como custo de oportunidade para o agricultor familiar o valor da remuneração que ele receberia no caso de não estar envolvido nas atividades do cultivo do fumo em sua propriedade.

Como forma de validação do modelo adotou-se para a remuneração das atividades das fases "1" a "3", como custo de oportunidade, um salário mínimo nacional, que segundo a maioria dos pesquisadores da área de agronegócios representa a remuneração compatível com o exercício da atividade rural dentro do âmbito da agricultura familiar, para a reprodução do trabalho.

Para as atividades exercidas durante as fases " 4 " a " 6 ", considerou-se a média ponderada consolidada da indústria fumageira de outubro de 2006 (relatório fornecido 
Proposição de um modelo de precificação de mão-de-obra como instrumento de gestão na atividade fumageira da região sul

Paulo Schmidt, Jose Luiz dos Santos, Luciane Alves Fernandes, Paulo Roberto Pinheiro

pelo Sindifumo), já que o custo de oportunidade do produtor rural familiar, nestas fases do processo, é igual a este valor, pois caso ele queira buscar uma colocação como terceirizado em outra propriedade teria relativa facilidade para conseguir, sendo esta a sua remuneração.

Corroborando na utilização do salário mínimo como referência para o custo de oportunidade, se considerou alguns trabalhos realizados na área de agronegócios por pesquisadores do Programa de Pós-Graduação strito-sensu em Agronegócios da Universidade Federal do Rio Grande do Sul (CEPAN-UFRGS), onde se percebeu os seguintes resultados:

- Pesquisa na produção de rosas - pesquisador Marcelo Badejo: a produção é estritamente familiar e a valorização dessa mão-de-obra tem como base o salário mínimo.

- Pesquisa sobre produção de leite na região Sul - pesquisador Francisco Isidro: pesquisa em propriedades leiteiras familiares indicando que a remuneração da produção deve considerar o salário mínimo mais um plano de saúde familiar, embora na prática, considerando uma pesquisa realizada em uma cooperativa leiteira, estava sendo considerado apenas o salário mínimo.

\subsection{Coeficiente técnico (dias/homem por hectare)}

Considerou-se o coeficiente técnico da produção do fumo Virginia na construção do modelo, sendo que para a utilização do modelo para os demais tipos de fumo basta alterar o coeficiente dias/homem por hectare do tipo de fumo para o qual será valorizada a mão-de-obra. 
Proposição de um modelo de precificação de mão-de-obra como instrumento de gestão na atividade fumageira da região sul

Paulo Schmidt, Jose Luiz dos Santos, Luciane Alves Fernandes, Paulo Roberto Pinheiro

\section{Modelo de valoração da mão de obra}

\begin{tabular}{|c|c|c|c|c|}
\hline custo mão de obra - & Modelo & DIÁRIA MÉDIA & $\mathbf{R} \$ \quad 33,82$ & base out/2006 \\
\hline ATIVIDADE & DIAS HOMEM POR HÁ & 1,0 & & TOTAL \\
\hline \begin{tabular}{|l} 
a1-Canteiro de Mudas \\
\end{tabular} & 9,64 & $\mathrm{R} \$ 16,91$ & & $\mathrm{R} \$ \quad 163,01$ \\
\hline a2-Plantio & 18,62 & $\mathrm{R} \$ 16,91$ & & $\mathrm{R} \$ \quad 314,86$ \\
\hline a3-Tratos Culturais & 28,46 & $\mathrm{R} \$ 16,91$ & & $\mathrm{R} \$ \quad 481,26$ \\
\hline a4-Colheita & 53,1 & $R \$ 33,82$ & & $\mathrm{R} \$ 1.795,84$ \\
\hline a5-Classificação & 36,21 & $R \$ 33,82$ & & $\mathrm{R} \$ 1.224,62$ \\
\hline a6-Serviços Diversos & 2,48 & $R \$ 33,82$ & & $\mathrm{R} \$ \quad 83,87$ \\
\hline $\begin{array}{l}\text { total } \\
\mathrm{R} \$ \text { /há }\end{array}$ & 148,51 & & & $\begin{array}{lr}R \$ & 4.063,47 \\
R \$ & 27,36\end{array}$ \\
\hline
\end{tabular}

Obs.: Diária média > Informação relatório de outubro/2006 (consolidado - Indústria) Cálculo da Média Ponderada da Diária Mão-de-Obra, fornecido pelo Sindifumo $=R \$$ 33,82 .

\section{Modelo de avaliação}

\begin{tabular}{|c|c|c|c|c|}
\hline \multirow{2}{*}{\multicolumn{2}{|c|}{ Custo de mão de obra - validação }} & \multirow{2}{*}{$\begin{array}{l}\text { salário mínimo } \\
\text { DIÁRIA MÉDIA }\end{array}$} & \multirow{3}{*}{$\begin{array}{lr}R \$ 350,00 \\
R \$ \quad 13,46 \\
\end{array}$} & \multirow{3}{*}{$\begin{array}{l}\text { dias úteis: } \\
\text { TOTAL }\end{array}$} \\
\hline & & & & \\
\hline ATIVIDADE & \multicolumn{2}{|c|}{ DIAS HOMEM POR HÁ (coeficiente técnico) } & & \\
\hline a1-Canteiro de Mudas & 9,64 & $\mathrm{R} \$ 13,46$ & & \begin{tabular}{|ll}
$\mathrm{R} \$$ & 129,77
\end{tabular} \\
\hline a2-Plantio & 18,62 & $R \$ 13,46$ & & $R \$ \quad 250,65$ \\
\hline a3-Tratos Custurais & 28,46 & $R \$ 13,46$ & & $R \$ 383,12$ \\
\hline a4-Colheita & 53,1 & $\mathrm{R} \$ 33,82$ & & $R \$ 1.795,84$ \\
\hline a5-Classificação & 36,21 & $R \$ 33,82$ & & $\mathrm{R} \$ 1.224,62$ \\
\hline a6- Serviços Diversos & 2,48 & $\mathrm{R} \$ 33,82$ & & 83,87 \\
\hline total & 148,51 & & & $\mathrm{R} \$ 3.867,88$ \\
\hline $\mathrm{R} \$$ /há & & & & $R \$ \quad 26,04$ \\
\hline
\end{tabular}

Obs.: Diária média $>\mathrm{R} \$ 350,00 \div 26$ dias trabalhados no mês $=\mathrm{R} \$ 13,46$

\section{CONCLUSÃO}

Considerando-se que não é praxe da cultura do fumo a remuneração por salário mínimo, optou-se pelo valor da remuneração média da terceirização da mão-de-obra, como um parâmetro da valorização da mão-de-obra familiar. Esse parâmetro está dentro de um contexto da área de agronegócio no Brasil, onde a remuneração da mãode-obra rural é fundamentada no salário mínimo e representa na atividade da cultura do 
Proposição de um modelo de precificação de mão-de-obra como instrumento de gestão na atividade fumageira da região sul

Paulo Schmidt, Jose Luiz dos Santos, Luciane Alves Fernandes, Paulo Roberto Pinheiro

fumo aproximadamente $55 \%$ do custo total de produção, base para a remuneração dos fumicultores.

A validação do modelo proposto, utilizando-se do custo de oportunidade para os fumicultores, demonstra que o parâmetro da média de mão-de-obra terceirizada está em conformidade com o salário mínimo, com um pequeno acréscimo e considerando as peculiaridades e especificações da cultura do fumo na região sul do Brasil.

\section{REFERÊNCIAS}

AFUBRA (Associação dos Fumicultores do Brasil). Disponível em: http: //www.afubra.com.br. Acesso em 05/out/2006.

BACKER, Morton \& JACOBSEN Lyle E. (1984). Contabilidade de custos: uma abordagem gerencial. (2 ed.). São Paulo, McGraw-Hill. p. 10.

FERREIRA, A. A. (1998). Características dos sistemas de produção, eficiência e economias de escala na produção de frango de corte no estado de Minas Gerais. Viçosa: UFV. (Dissertação de Mestrado).

IÓRIO, M. C. de O. (1994). A modernização agroindustrial: sindicalismo ante uma versão agrária da terceirização. In: MARTINS, H. de S.; RAMALHO, J. R. Terceirização e Negociação no Mundo do Trabalho. São Paulo: HUCITEC: CEDI/NETS, p.137-152.

JORDE, T. M.; TEECE, D. J. (1989). Competition and cooperation: striking the right balance. Business e Public Policy.

LEIWINGER, Wayne E. (1977). Opportunity cost: some definitions and examples. The accounting Review. 52(1)248-251, january. p. 249 e 251.

Ministério do Desenvolvimento Agrário/INCRA. (2000). Novo Retrato da Agricultura Familiar. O Brasil redescoberto. Brasília: MDA/INCRA. 74p.

MORSE, Wayne \& ROTH, Harold P. (1986). Cost accounting: processing, evaluating and using cost data. ( 3 ed.). Reading, Massachusetts, Addison-Wesley Publishing. p. 36-37.

RAMÍREZ, E. P. \& FOSTER, W. (2003). Analises de la Oferta de Mano de Obra Familiar em la Agricultura Campesina de Chile. Cuadernos de Economía, Año 40, № 119, pp. 89-110. Abril. 
Proposição de um modelo de precificação de mão-de-obra como instrumento de gestão na atividade fumageira da região sul

Paulo Schmidt, Jose Luiz dos Santos, Luciane Alves Fernandes, Paulo Roberto Pinheiro

SINDIFUMO (Sindicato da indústria do fumo). Disponível em: www.sindifumo.com.br. Acesso em: 02/out/2006.

SPEKMAN, R. E.; KAMAUFF Jr, J. W.; MYHR, N. (1998). An empirical investigation into supply chain management - A perspective on partnerships. International Journal of Physical Distribution and Logistics Management, v. 28, n. 8, p.630-650.

ZAWISLAK, P. A. (2000). Alianças estratégicas: contexto e conceitos para um modelo de gestão. Saberes, v. 1, n. 3, p. $10-21$, set./dez.

Data de Submissão: 15/10/2009

Data de Aceite: 11/12/2009 